\title{
Evaluation of Societal Trust on Multi-Hazard Early Warning (MHEW) Mechanism; Sri Lankan Context
}

Purpose - It is significant to assess the societal trust towards the new advancements in Multi-Hazard Early Warnings with the focus on Disaster Risk Reduction. Based on this, the research is undertaken to examine the extent of societal trust behavior along with the parameters such as mode of communication and institutions of issuing Early Warnings.

Design/methodology/approach - A field questionnaire survey was conducted to identify the extent of societal trust. This was conducted in 10 selected Grama Niladari divisions in Sri Lanka based on a developed hazard matrix. The fuzzy logic approach was applied to examine the trust level of collected 323 responses obtained through this. The analysis was done based on the responses on mobile-based platforms in Early Warning and the credibility level of the warnings receive through different institutions.

Findings - The analyzed survey responses indicated that the society has a higher extent of trust towards the Early Warnings disseminated through mobile-based platforms. Moreover, these represent a strong positive correlation among the societal trust level and the level of importance of Early Warning dissemination through mobile-based platforms. Further, in terms of trusted stakeholders in issuing Early Warning alerts, Disaster Management Center, Sri Lanka Police and Media ranked the highest in the Sri Lankan context. Overall findings were visually mapped through the Causal Loop Diagrams.

Practical implications - In enhancing the effectiveness of the existing Multi-Hazard Early Warning mechanism, the policy implications could be done, based on the results obtained from this research study. These could be altered with the implementation of Disaster Risk Reduction strategies with community focus.

Originality/value - The fuzzy logic approach was used in the determination of the societal decision making on the extent of trust level. Fuzzy triangulation is mainly applied in the interpretation of the results. Further, overall parameters that determine the community trust on Multi-Hazard Early Warning are represented through Causal Loop Diagrams through System Dynamics application.

Keywords: Societal trust, Fuzzy Logic approach, Multi-Hazard Early Warning (MHEW), Disasters, Causal Loop Diagrams, Mobile based platforms 


\section{Introduction}

Trustworthiness is simply defined as the worthy of confidence in an expression [1]. In linking this to the disaster management perspectives, it is considered as an important determinant of shaping the social perception of risk during emergency disaster situations [2]. To achieve the targeted level of risk reduction in disaster situations, the community level as well as the institutional level trust, needs to be properly achieved. In defining these aspects of trust behaviors in emergency disaster situations, political trust and societal trust are highly significant [3]. Political trust deals with the positive appraisal delivered by citizens with the faith in the country's government and the authorities and societal trust deals with the positive attitudes and faith that build among the community individuals [3]. Further, the extent of societal trust is considered as a lubricant in the country's Early Warning mechanism where the actions and the guidelines wheel into the correct path in the Disaster Management framework [4]. This was further involved with the emerging of the Multi-Hazard Early Warning (MHEW) concepts where the Disaster Risk Reduction (DRR) strategies were integrated with the focus of multi-hazards rather than one specific hazard category [5]. Societal involvement in this MHEW mechanism is considered more significant in driving public safety through safe evacuation [6]. MHEW mechanisms are commonly defined as the applications which are used during the identification of hazard warnings to reduce life threats and mitigate damages caused to the properties [7]. The term "Multi-Hazard" is defined as the selection of multiple major hazards that the country faces, and the specific contexts where hazardous events may occur simultaneously, cascading or cumulatively over time, and taking into account the potential interrelated effects. Hazards here include mainly the biological, environmental, geological, hydro-meteorological and technological processes and phenomena [8]. The function of MHEW is considered to be defined as a systematic approach of conveying information to the community level who are vulnerable to the risk of an identified hazard in advance of physical effects [9]. Moreover, the effectiveness of MHEW can be measured depending on factors like level of understanding of the hazard type, credibility of the issuing agency and peoples' perception of the danger [10]. In the context of DRR, the efficient functioning of MHEWs emerged as a critical concern over the world [11]. The effective MHEW mechanism mainly comprises of four elements as detection, monitoring and forecasting, analysis of risks involved, dissemination of timely warnings-which should carry the authority of government and activation of emergency plans to prepare and respond [12]. Further, as defined by World Meteorological Organization (WMO), the main elements in MHEW are ordered as disaster risk knowledge, detection, monitoring, analysis and forecasting of the hazards, warning dissemination and communication and preparedness and response capabilities [13]. Further, this mechanism of MHEW is defined as an upstream, interface and downstream levels based upon different hierarchical levels of the information flow [14].

Concerning the recent mass evacuation conducted for the Fani category 4 cyclone in Odisha in India which struck in 2019, 1.2 million communities were successfully able to evacuate and sending them to shelter places. This induced to reduce the massive damage 
that could have happened in the country [15]. The societal trust level was at its highest level when the EWs were delivered at the correct time and accurate content [16]. Another major example was Cuba's tropical cyclone in which the EWs were delivered at an appropriate time and massive evacuation of the society was conducted [17]. This too highlights the societal level of trust that has created along with the people towards the existing EW mechanisms in the country.

Further, concerning the recent disaster events in Sri Lanka, the Indian Ocean tsunami incident in 2004 and the Meethotamulla garbage dump collapse in 2017 denote that lack of societal level trust had led to a disastrous calamity over the lives and property of the community[18]. Especially during the Meethotamulla garbage dump failure, the society was aware several times to evacuate from the location. But the ignorance of the repeated warnings made huge disaster damage to the community as well as to the infrastructure. In all these incidents, the damage to infrastructure and life losses could have minimized to a greater extent if the trust level of the society and timely delivery of the MHEWs were given to evacuate the community. Another most recent incident in Sri Lanka was the MHEWs delivered for the cyclone Burevi in 2020 in which nearly 75000 people were safely evacuated [19]. In this incident, before the cyclone landfall was hitting the island, the community around the areas were evacuated to safer places. This denotes where the societal trust towards the MHEWs elaborated with the severity of the incidents.

As to further initiate the preparedness of the coastal communities and enhancing the trust levels, the recent desktop exercise of IOWave 2020 was conducted in Sri Lanka [20]. Here, the Disaster Management Center (DMC) pioneered the exercise as the leading government authority in Disaster Management in Sri Lanka. As the key decision-making authority in MHEW dissemination towards the societal level, DMC has the government endorsement in action making in disaster emergencies. In this exercise, due to the miscommunication by the Divisional Secretariat divisions in certain coastal communities, the warnings delivered were impacted to create a panic situation in the areas. This too denotes how the miscommunication of the information could lead to the mistrust of the EWs delivered through the responsible authorities.

\subsection{Situations of Societal Mistrust in Multi-Hazard Early Warnings}

In the recent disaster events, this nature of MHEWs delivered in emergencies has made confusion among the societies and had led towards the mistrust of the EWs. The repetition of dissemination of such mistrusted warning alerts and as well as false warnings is an indication of poor societal trust. These can further lead towards lack of preparedness in the societies in related to the actual disaster situations which can trigger mas sive damages.

Some such recent disaster incidents in the global level in which the trust in the EWs got disrupted are represented in Table 1. 
Table 1 Recent disaster incidents

\begin{tabular}{|l|l|l|l|l|}
\hline Year & Country & Disaster & Key issues & Reference \\
\hline 2005 & $\begin{array}{l}\text { Sunda } \\
\text { Trench }\end{array}$ & Tsunami & False alarm for Tsunami & {$[9]$} \\
\hline 2007 & Bangladesh & Cyclone Sidr & $\begin{array}{l}\text { Too many false alarms } \\
\text { Victims have not responded to } \\
\text { alarms and warnings }\end{array}$ & {$[21],[22]$} \\
\hline 2007 & $\begin{array}{l}\text { Aceh, } \\
\text { Indonesia }\end{array}$ & Tsunami in Aceh & $\begin{array}{l}\text { False alarm for Tsunami } \\
\text { caused mass panic in the } \\
\text { community }\end{array}$ & {$[23]$} \\
\hline 2012 & $\begin{array}{l}\text { United } \\
\text { States }\end{array}$ & Hurricane Sandy & $\begin{array}{l}\text { Not issuing critical warnings } \\
\text { to evacuate }\end{array}$ & {$[24]$} \\
\hline 2018 & $\begin{array}{l}\text { Palu, } \\
\text { Indonesia }\end{array}$ & $\begin{array}{l}\text { Earthquake and } \\
\text { Tsunami }\end{array}$ & $\begin{array}{l}\text { A false sense of security of the } \\
\text { warnings }\end{array}$ & {$[25]$} \\
\hline
\end{tabular}

These impacts have become more crucial mainly due to the lack of preparedness of the communities and inability to take necessary actions in safely evacuating before the disasters strike. Further, the false sense of emergency warnings and too many false alarms from the past disaster experiences make the society more confused towards trusting the MHEWs disseminated through respective institutions.

\subsection{Determining Parameters of Societal Trust to Multi-Hazard Early Warnings}

Based on the above focused incidents, the main determining parameters which have influenced the variety of societal trust level on the EWs delivered at emergencies are denoted below Table 2 . In the delivery of effective warning messages to the vulnerable community, these parameters are more significant to develop trust in the warnings issued.

Table 2 Overview of parameters

\begin{tabular}{|l|l|}
\hline Paramete rs & Refe re nce \\
\hline Incomplete information & {$[9]$} \\
\hline Accuracy of the information & {$[26],[27]$} \\
\hline Too many false alarms & {$[9],[27]$} \\
\hline Content of the warning & {$[3]$} \\
\hline Frequently updated warnings & {$[28]$} \\
\hline Modes of warning dissemination & {$[29],[30],[9],[28],[27]$} \\
\hline Scientific evidence based warnings & {$[28]$} \\
\hline Consistency of the messages over time & {$[28]$} \\
\hline
\end{tabular}




\begin{tabular}{|l|l|}
\hline Repetitive warning messages & {$[31]$} \\
\hline Respective authority of warning issuing & {$[3],[32]$} \\
\hline
\end{tabular}

The afore-mentioned key parameters were mainly examined through the survey studies which were conducted in most of the recent studies [33]. Among these parameters, the mode of warning dissemination plays a major role [29]. Based on the efficiency, effectiveness and accessibility of the modes of EW dissemination, the trust levels of the societies mainly vary. The traditional communication modes such as television, radio and EW towers are now replaced with the modern technology platforms such as mobile based platforms and social media platforms [34]. Further, the authorities which issue the EWs are another major factor on which societal trust is dependent [35], [36]. Based on the endorsement provided by the governmental bodies in the countries, the trust level upon the societies is mainly dependent. These factors further vary with the variables such as age categories, gender categories and as well as the urban and rural level societal behaviours.

The preparedness of the community could be enhanced further through the boosting of focus on gender responsive and youth engaging training practices [37], [38]. In Cambodia, the gender gap on mitigating the EWs during emergency disaster situations was elaborated through the perception determination from each of male and female categories [37]. This was more highlighted with the focus on unequal access to and control of natural resources, unbalanced participation in decision making and uneven access to socio economic benefits and services. The results here mainly elaborate that gender needs to be concerned as a key priority in disaster risk reduction mechanism. Based on their findings, as most of the women are engages with house holding activities, the mainstreaming of gender based policies in enhancing the preparedness of community in national policies was considered highly needful.

Another study in Nepal and Peru too highlight the fact that, gender sensitive disaster risk reduction mechanisms are a key lag in most of the developing countries in the world [39]. Here, the focus is directed on implementing DRR policy implications which are supported with gender awareness, gender sensitivity and gender transformative Early Warning mechanisms. The focus was more elaborated with the key findings of the study which was done on vulnerability, participation, dissemination, response and power in decision making related with Early Warning mechanism.

From these identifications, it is denoted that depending on the trust level variations, the percentage of acceptance of the EWs is varied. With the novel developing concepts integrated with the MHEW mechanism, countries are now tending to strengthen the trust level among the societies towards the level of acceptance of the EWs. Incorporating with this, technology plays a vital role. This is mainly because, technological aspects mainly enhances the effectiveness and efficiency of the MHEWs [40]. Along with these global level advancements, Sri Lanka too is in the process of adapting new mechanisms in the context of delivering MHEW alerts to the community level [41], [29]. In the Sri Lankan context, the initial studies denote the coastal community response towards the existing Tsunami Early Warning mechanism [42], [43], [44]. According to the recent findings, 75\% 
of the coastal community has lost faith in Early Warning information and $60 \%$ are reluctant to respond to Early Warnings given [33], [35]. With that breakdown being a critical concern and challenges to overcome, it is required to study the factors behind these in a broader sense. Further, these studies have focused only on the coastal community perspective in Sri Lanka and the exposure towards the existing traditional modes of communication and more specific towards the tsunami EWs. Along with these survey studies, the focus was delivered mainly upon the community preference on communication modes of warning dissemination, accessibility towards the EW towers which are implemented in the respective areas and effectiveness of such implemented EW towers based on the previous experience [33]. Another similar study has focussed on identifying the gaps in the existing EW procedures and evacuation practices in the coastal community [45]. Mainly the findings in here were categoried under five themes of response to EW systems, evacuation routes, shelters, drills and training, effect of having a family vehicle, relatives and domestic animals, evacuation of people with special needs and cooperation with local government units [45].

Concerning the existing mechanism of EWs, the Short Message Service (SMS) is currently undertaken to disseminate the EW message to a selected set of people who are interlinked with the disaster management mechanism in Sri Lanka. These sorted sets of first responders were made aware through the SMS alert system to make the community get aware. Along with the focus on these parameters, the relationship among each of the identified parameters has been examined in recent research studies. These relationships have been identified in determining the variation of trust level along with the parameter variations. Some such identified correlation relationships are presented in below Table 3 .

Table 3 Relationship among the identified factors

\begin{tabular}{|l|l|l|}
\hline Identified factor & $\begin{array}{l}\text { Relationship with } \\
\text { the trust of the EW }\end{array}$ & References \\
\hline $\begin{array}{l}\text { Importance of societal trust } \\
\text { Familiarity with the hazard }\end{array}$ & Inversely related & {$[46]$} \\
\hline Institutional trust and place attachment & Positively related & {$[47]$} \\
\hline Interpersonal trust and place attachment & Positively related & {$[47]$} \\
\hline $\begin{array}{l}\text { Trust in administrative bodies and } \\
\text { acceptance of flood risks }\end{array}$ & Positively related & {$[48],[49]$} \\
\hline $\begin{array}{l}\text { Trust on Emergency Management and } \\
\text { institutional collaboration }\end{array}$ & Positively related & {$[50]$} \\
\hline Trust and availability of the information & Positively related & {$[46]$} \\
\hline
\end{tabular}

Under this research study, the societal trust level on the EW alert given based on the mobile phones was evaluated comparing the urban and rural level comparison of results. This needs to be identified properly in exploring the societal adaptation towards modern EW applications interlinked with the technology. Further, this study is more focused on 
the identification of the perception of societal trust level towards the key stakeholders who are interlinked with the dissemination of the EW message to the end-users.

\section{Approaches to Examine Trust Behaviors}

Societal trust is considered more significant in the determination of loyalty towards different aspects of a system [51]. In determining such perspectives, different analytical techniques can be used. The perceptions of the societies are varied over the human behaviors which change over time. Based on these and the external factor influences, the human perception patterns can be varied with the focus of trust behaviors. Different research examinations have undertaken to determine the trust behaviors which are variating with the human behaviors of people. Some such used research techniques are denoted in Table 4.

Table 4 Research Techniques

\begin{tabular}{|l|l|}
\hline Technique & Refe rences \\
\hline Fuzzy logic approach & {$[52],[53],[54],[55],[56]$} \\
\hline Conceptual modelling & {$[57],[58],[59]$} \\
\hline Realist logic analysis & {$[60],[61],[62]$} \\
\hline Agent based modelling & {$[63],[64],[65]$} \\
\hline Multi variate analysis & {$[21],[66]$} \\
\hline
\end{tabular}

Among the afore mentioned approaches, the fuzzy Logic approach is one of the most commonly used techniques which is used in determining the level of uncertainty to solve the problems which are too complex to be solved [67]. This approach mainly deals with fuzzy parameters, which determine the level of uncertainties in the considered parameters. The fuzzy scale ranking is mainly used to determine qualitative human thinking into valuations and ratings [68]. This approach is used most commonly in converting linguistic scale ("strongly disagree", "disagree", "fair", "agree" and "strongly agree") into a five point Likert scale $(1,2,3,4,5)$ in which human thinking is subjective and responses may lead to unreasonable results.

Fuzzy set theory was defined to determine these fuzzy triangulation numbers to convert the linguistic variables to quantitative values. This is performed by taking into account the uncertainty in the decision-making process of people [69]. For instance, a triangular fuzzy number that corresponds to the linguistic variable "average" can be defined as $Y=(c, a$, $b)=(2,3,4)$. This is performed by indicating that the decision-makers grade a service they refer to as "average" by a numerical value of minimum 2 , on average 3 , and maximum 4 . Moreover, several arithmetic operations can be defined on fuzzy numbers depending on the form of the number. For instance, the addition, subtraction and multiplication operations on triangular fuzzy numbers are represented as below.

$$
\begin{array}{lll}
(\mathrm{L} 1, \mathrm{M} 1, \mathrm{~N} 1)+(\mathrm{L} 2, \mathrm{M} 2, \mathrm{~N} 2) & = & (\mathrm{L} 1+\mathrm{L} 2, \mathrm{M} 1+\mathrm{M} 2, \mathrm{~N} 1+\mathrm{N} 2) \\
(\mathrm{L} 1, \mathrm{M} 1, \mathrm{~N} 1)-(\mathrm{L} 2, \mathrm{M} 2, \mathrm{~N} 2) & = & (\mathrm{L} 1-\mathrm{L} 2, \mathrm{M} 1-\mathrm{M} 2, \mathrm{~N} 1-\mathrm{N} 2)
\end{array}
$$




$$
(\mathrm{L} 1, \mathrm{M} 1, \mathrm{~N} 1) *(\mathrm{~L} 2, \mathrm{M} 2, \mathrm{~N} 2)=(\mathrm{L} 1 * \mathrm{~L} 2, \mathrm{M} 1 * \mathrm{M} 2, \mathrm{~N} 1 * \mathrm{~N} 2)
$$

These can be considered in using the determination of the triangular fuzzy numbers in delivering the most suited decision making criteria in the Likert scale responses.

The representation of the fuzzy triangulation number $(\mathrm{x} 1, \mathrm{x} 2, \mathrm{x} 3)$, with the interpretation of the minimum, kernel and maximum values is represented below Figure 1 .

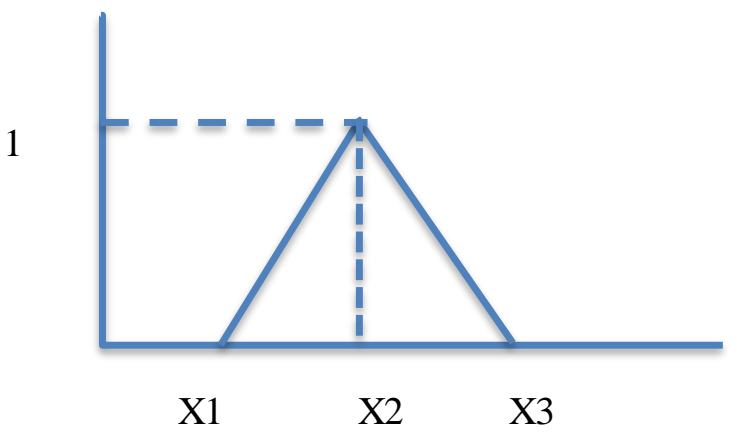

Figure 1 Triangular fuzzy number

Based on the above considerations, the application of the fuzzy logic approach is considered here in this extent of trust level determination. This was mainly considered with the examination of the community trust behaviors through the Likert scale marking of the responses of the community. Through this approach, more realistic decision making on human thinking patterns can be examined.

\section{Methodology}

In following this research study, firstly a desk study was conducted to examine the societal trust in the context of global and Sri Lankan level. With this background study and review of recent research studies based on the Sri Lankan aspect, a questionnaire survey was developed. For the determination of the sample size, a random sampling technique was chosen after the statistical examination. To conduct this research survey study, the location identification was done based on a hazard matrix developed. This was developed based on the previous disaster risks for the critical hazard categories in Sri Lanka, which are floods, tsunami, landslides, heavy winds and droughts. The areas in the Western Province which are having higher risks to above-mentioned disaster situations were considered for the examination. Here, face-to-face interviewing was carried as the approach to collect responses in the questionnaire survey. In reaching the community to collect the parameters in the questionnaire survey, the interviewing was more effective rather than distribution of the survey sheets and asking them to complete. This was reached with the initial pilot study of distribution of questionnaire survey among a selected community group in the society. 
A randomly selected sample of community representation in each of the Grama Niladari divisions was chosen for this study.

As the base of the research study, the following perspectives of the societal trust level represented under Figure 2 were examined. To identify the societal level of trust in the existing MHEW mechanism in Sri Lanka, the focus needs to be concerned with urban and rural level perceptions of the community.

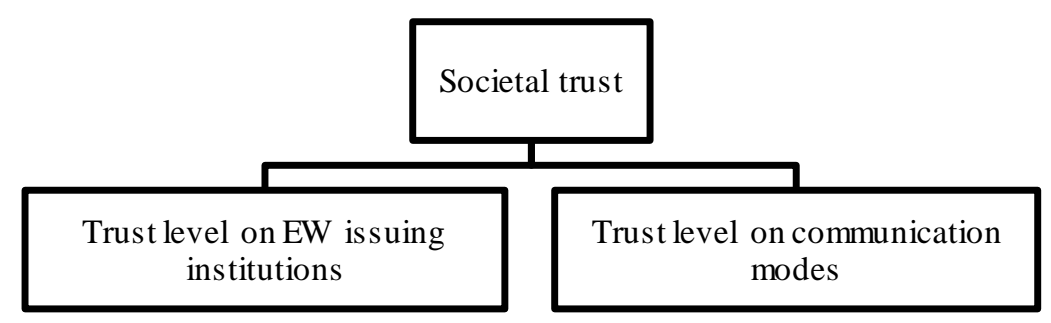

Figure 2 Focusing areas of community trust level

\section{Data collection}

The questionnaire survey was developed using 15 questions and here as the main concern, the societal trust level was examined under a separate section. The overall questionnaire was structured based on the flow chart which initiated the structure of the questionnaire survey. To identify the societal trust in the EWs delivered through mobilebased technology, a five point Likert scale was used. In the same manner, the identification of the most trusted authorities was determined through the ranking system of the top 5 most authorities in terms of issuing EW alerts to the communities.

To conduct the questionnaire survey, the study locations were selected based on the hazard level of the Grama Niladari (GN) divisions in Sri Lanka based on the risks for floods, landslides and tsunami [70]. Accordingly, the 10 mostly hazard-prone GN divisions were chosen to conduct the questionnaire survey. As per the selected study locations, the field data collection was undertaken in the selected 10 Grama Niladari divisions. Accordingly, the overall summary of the responses collected from each Grama Niladari division is represented under the below Table 5 .

Table 5 Data Collection Summary

\begin{tabular}{|c|l|l|c|}
\hline District & DS Division & GN Division & $\begin{array}{l}\text { Number of } \\
\text { Responses }\end{array}$ \\
\hline Kalutara & Bulathsinhala & Bothalegangoda & 33 \\
\hline & & Paragoda East & 39 \\
\hline & & Yatagampitiya & 36 \\
\hline & & Amaragedara South & 33 \\
\hline
\end{tabular}




\begin{tabular}{|l|l|l|c|}
\hline Gampaha & Wattala & Paranambalama & 34 \\
\hline & & Us wetakeiyya & 34 \\
\hline & & Dikowita & 32 \\
\hline Colombo & Colombo & Grandpass South & 28 \\
\hline & & Mattakkuliya & 27 \\
\hline & & Modara & 27 \\
\hline Total & & & 323 \\
\hline
\end{tabular}

According to the responses received from the field questionnaire survey, the societal trust level was examined with the analysis of the data. The demography of the responders of the questionnaire survey is denoted under Table 6. Accordingly, the background of the responders are presented here.

Table 6 Demographic Information on the Responders

\begin{tabular}{|l|l|c|}
\hline Variable & Category & Percentage (\%) \\
\hline \multirow{4}{*}{ Gender } & Male & 47 \\
\cline { 2 - 3 } & Female & 53 \\
\hline \multirow{5}{*}{ Occupation category } & Below 18 & 4 \\
\cline { 2 - 3 } & $18-24$ years & 8 \\
\cline { 2 - 3 } & $25-39$ years & 29 \\
\cline { 2 - 3 } & $40-60$ years & 44 \\
\cline { 2 - 3 } & Over 60 years & 15 \\
\hline & Government sector & 6 \\
\cline { 2 - 3 } & Private sector & 17 \\
\cline { 2 - 3 } & Self employed & 25 \\
\cline { 2 - 3 } & Student (school) & 5 \\
\cline { 2 - 3 } & Student (university) & 2 \\
\cline { 2 - 3 } & Others (no job, retired) & 45 \\
\hline
\end{tabular}

\section{Data analysis}

\subsection{Reliability of the Collected Data}

The reliability of data was determined and verified using a reliability coefficient named Cronbach alpha which is denoted in Eq.(1). When the Cronbach alpha is less than 0.3, the data is considered not suitable for further analysis as the reliability level of data is considered as low. When the Cronbach alpha is more than 0.7, data is considered suitable for further analysis as the reliability level is considered high [71].

$$
\propto=\frac{N \bar{c}}{\bar{v}+(N-1) \bar{c}} \quad \text { Eq. }(1)
$$

$\begin{array}{lll}\propto & = & \text { Cronbach alpha } \\ N & = & \text { Number of items } \\ \bar{c} & = & \text { Average covariance between item pairs } \\ \bar{v} & = & \text { Average variance }\end{array}$


The Cronbach alpha was determined through IBM SPSS 22 software and the obtained value for Cronbach alpha was 0.704 . Accordingly, data could be used for further research analysis. The results obtained from the software analysis are represented under the belowmentioned Table 7.

Table 7 Case processing summary from IBM SPSS 22 software

\begin{tabular}{|c|c|c|c|}
\hline \multicolumn{4}{|c|}{ Case Processing Summary } \\
\hline & & $\mathbf{N}$ & $\%$ \\
\hline \multirow{3}{*}{ Cases } & Valid & 295 & 91.3 \\
\hline & Excluded & 28 & 8.7 \\
\hline & Total & 323 & 100.0 \\
\hline Cronbach alpha & \multicolumn{3}{|c|}{0.704} \\
\hline
\end{tabular}

\subsection{Application of Fuzzy Logic to Assess Community Level Trust}

Five points Likert scale was used in the questionnaire survey to determine the trust level of the society on the existing Early Warning mechanism in Sri Lanka. In determining the most appropriate response based on the responses received from the Likert scale data the triangular fuzzy number was considered to be determined. Triangular fuzzy number $\mathrm{X}$ can be represented based on the triplet $(\mathrm{x} 1, \mathrm{x} 2, \mathrm{x} 3)$ which is determined from the three value judgment for a considered response concerning minimum possible value $\mathrm{x} 1$, Kernel value $\mathrm{x} 2$ and most possible value $\mathrm{x} 2$ and maximum possible value $\mathrm{x} 3$ [72]. Based on the same category of five points Likert scale developed on the determination of triangular fuzzy numbers, the fuzzy correspondences which are represented under Table 8 were identified for the analysis [73]. This was applied for the frequencies of each score collected from the data collection which is denoted in Table 9.

Table 8 Fuzzy Correspondences

\begin{tabular}{|l|l|}
\hline Variable & Fuzzy correspondences \\
\hline Unlikely & $(1.0,1.0,2.0)$ \\
\hline Somewhat unlikely & $(1.0,2.0,3.0)$ \\
\hline Moderate & $(2.0,3.0,4.0)$ \\
\hline Somewhat likely & $(3.0,4.0,5.0)$ \\
\hline Extremely likely & $(4.0,5.0,5.0)$ \\
\hline
\end{tabular}


Table 9 Sample Frequency Table

\begin{tabular}{|l|l|l|l|l|l|}
\hline Score & $\mathbf{1}$ & $\mathbf{2}$ & $\mathbf{3}$ & $\mathbf{4}$ & $\mathbf{5}$ \\
\hline Frequency & 3 & 9 & 5 & 50 & 254 \\
\hline
\end{tabular}

Taking the average fuzzy score based on the results obtained in the frequency table, the average weighted score for each Triangular Fuzzy Number (TFN) is calculated as below Table 10. This was determined to identify the weighted average fuzzy score which suits the most appropriate based on the Likert scale score variation from the questionnaire survey responses.

Table 10 Average Weighted S core

\begin{tabular}{|l|l|}
\hline Parameter & Value \\
\hline $\begin{array}{l}\text { Average weighted score } \\
\text { for Fuzzy Triangulation } \\
\text { Number }\end{array}$ & $(1.0,1.0,2.0) * 3+(1.0,2.0,3.0) * 9+(2.0,3.0,4.0) * 5+(3.0$, \\
& $(3.7,4.6,4.8)$ \\
\cline { 2 - 2 } & \\
\hline
\end{tabular}

In this formulation, the Kernal value is identical to the weighted average (or mean score) recorded. Accordingly, the most appropriate response based on the triangular fuzzy number was considered as 4.6 which represents the high level of extreme likeliness towards the trust on EWs delivered through mobile-based technologies.

\subsection{Comparison of Urban and Rural Level Responses}

In the Sri Lankan context, the comparison of urban and rural level responses based on the societal trust level is needed to be examined. Accordingly, the following categorization of the study locations represented under Table 11 can be identified as urban and rural areas in Sri Lanka. This is determined based on the population density as the main parameter in classifying the urban and rural categorization.

Table 11 Population density of the study locations

\begin{tabular}{|c|c|c|c|}
\hline DS Division & Population (2012 Census) & $\begin{array}{ll}\text { Land } & \text { Area } \\
(\mathrm{km} 2) & \end{array}$ & $\begin{array}{l}\text { Population Density } \\
\text { (population/km2) }\end{array}$ \\
\hline Colombo & 323,257 & 18 & 17,959 \\
\hline Wattala & 175,525 & 54 & 3250 \\
\hline Bulathsinhala & 64,600 & 206 & 313 \\
\hline
\end{tabular}

Based on the recent research studies done in Sri Lanka, the urbanization of the administrative divisions of the country was determined based on the population density in each land area [74]. The areas where the population density exceeds 500 persons per 
square kilometer are considered urbanized in the Sri Lankan context. Accordingly, from the sorted study locations, Colombo and Wattala Divisional Secretariat (DS divisions) are considered as urbanized and Bulathsinhala DS division is considered as rural in the context of population density.

Based on the above considerations, the societal trust level variation on the Early Warning messages delivered through mobile phones was examined. This was assessed mainly through the fuzzy logic approach in which the most appropriate response given through the sample community is sorted. The decision matrix represented under Table 12 denotes the summary of the fuzzy triangulation numbers in urban and rural perspectives.

Table 12 Decision Matrix in Urban and Rural Level

\begin{tabular}{|c|c|c|c|c|c|c|c|c|c|c|}
\hline Parameter & \multicolumn{5}{|c|}{ Urban level } & \multicolumn{5}{|c|}{ Rural level } \\
\hline Likert scale score & 1 & 2 & 3 & 4 & 5 & 1 & 2 & 3 & 4 & 5 \\
\hline Frequency & 0 & 1 & 8 & 17 & 156 & 4 & 6 & 1 & 11 & 116 \\
\hline \multirow{2}{*}{$\begin{array}{l}\text { Average weighted score } \\
\text { for Fuzzy Triangulation } \\
\text { Number }\end{array}$} & \multicolumn{5}{|c|}{$\begin{array}{l}(1.0,1.0,2.0) * 0+(1.0,2.0,3.0) * 1+(2.0, \\
3.0,4.0) * 8+(3.0,4.0,5.0) * 17+(4.0, \\
5.0,5.0) * 156 / 182\end{array}$} & \multicolumn{5}{|c|}{$\begin{array}{l}(1.0,1.0,2.0) * 4+(1.0,2.0,3.0) * 6 \\
+(2.0,3.0,4.0) * 1+(3.0,4.0 \\
5.0)^{*} 11+(4.0,5.0,5.0) * 116 / 138\end{array}$} \\
\hline & \multicolumn{5}{|c|}{$(3.8,4.8,4.9)$} & \multicolumn{5}{|c|}{$(3.7,4.6,4.8)$} \\
\hline
\end{tabular}

Accordingly, when compared the triangular fuzzy numbers obtained for urban and rural level responses, the urban level trust level is more biased towards an extreme level of trust which is more than score 4 of the Likert scale. In the same manner, the rural level fuzzy triangulation number of 4.6 denotes the extreme level of trust towards mobile based platforms which is also greater than score 4 of the Likert scale.

\subsection{Correlation Determination}

In the further analysis of trust level determination, the correlation of determination $\left(\mathrm{r}^{2}\right)$ was examined. This was mainly evaluated to determine how strong the variation of the two variables impacts each other. Through this, the measurement of variation of the community trust level along with the impact on the variation of the level of importance of EWs dissemination through mobile phones was undertaken. This was examined with the application of IBM SPSS 22 software. Here, the behavior of the two variables with the trend line patterns of polynomial, linear, exponential, logarithmic and power variations are represented under the below Table 13.

Table 13 Trend line behavior variation

\begin{tabular}{|l|c|}
\hline Trend line behaviors & Value of the $\mathrm{r}^{2}$ \\
\hline Polynomial & 0.7060 \\
\hline Linear & 0.7016 \\
\hline Exponential & 0.6793 \\
\hline
\end{tabular}




\begin{tabular}{|l|c|}
\hline Logarithmic & 0.7029 \\
\hline Power & 0.6967 \\
\hline
\end{tabular}

Based on the results obtained for the correlation of determination value, the highest value representation is represented through the polynomial behavior relationship among the two variables. It is considered that the $\mathrm{r}^{2}$ closer to 1 provides the highest correlation of determination value among the two variables. Accordingly, here the two variables denote a polynomial behavior of relationship among each of their variations. This is graphically illustrated through the graph denoted in Figure 3.

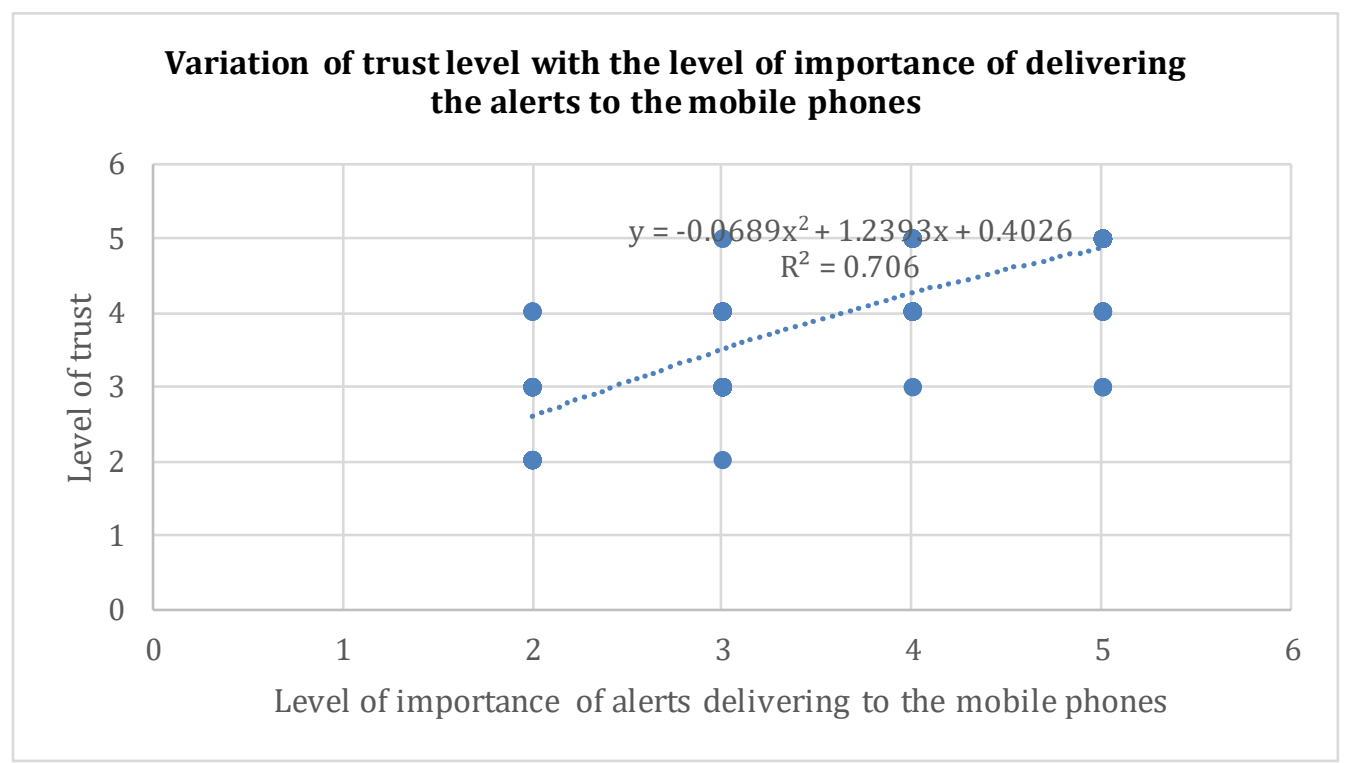

Figure 3 Variation of community trust level along with the level of importance of EW disseminatior through mobile phones

From the statistical data analysis approached based on correlation determination, it has represented that $\mathrm{r}^{2}$ value varies from -1 to +1 representing the negative correlation behaviors from -1 to 0 and positive correlation behaviors from 0 to +1 [75], [76]. Here as the coefficient of determination value is greater than 0.7 , it is considered that there is a strong positive correlation between the increase of societal trust level along with the level of importance of dissemination of the EWs through mobile phone technologies [77].

\subsection{Societal Trust Level on the Authorities in terms of Issuing Early Warning Alerts}

Based on the responses received from the questionnaire survey, the ranking of the institutions based on the trust level in terms of issuing disaster EW alerts was examined. Accordingly, the following authorities were considered for the ranking of the trust level which was identified from the previous research study done in Sri Lanka, to identify the main stakeholders who are interlinked with the dissemination of EW messages to the 
community level [35]. In this study, only the main stakeholders who were common in most of the selected disaster categories were considered floods, tsunami and landslides, which were considered for the study area selection as well. Here, the communication network models have developed using the existing Emergency Operation Procedures (EOPs) in Sri Lanka with the application of the Social Network Analysis (SNA) approach. With this, the key stakeholders were identified with the use of degree centrality parameters under the analysis of the modeled networks.

Given below is the overview of the results obtained for the trust level of authorities based on the categorization of ranking, age category, gender category and the study locations based on urban and rural levels. Below mentioned Figure 4 represents the overview of the top 5 ranked institutions where the trust is based in terms of issuing EW alerts.

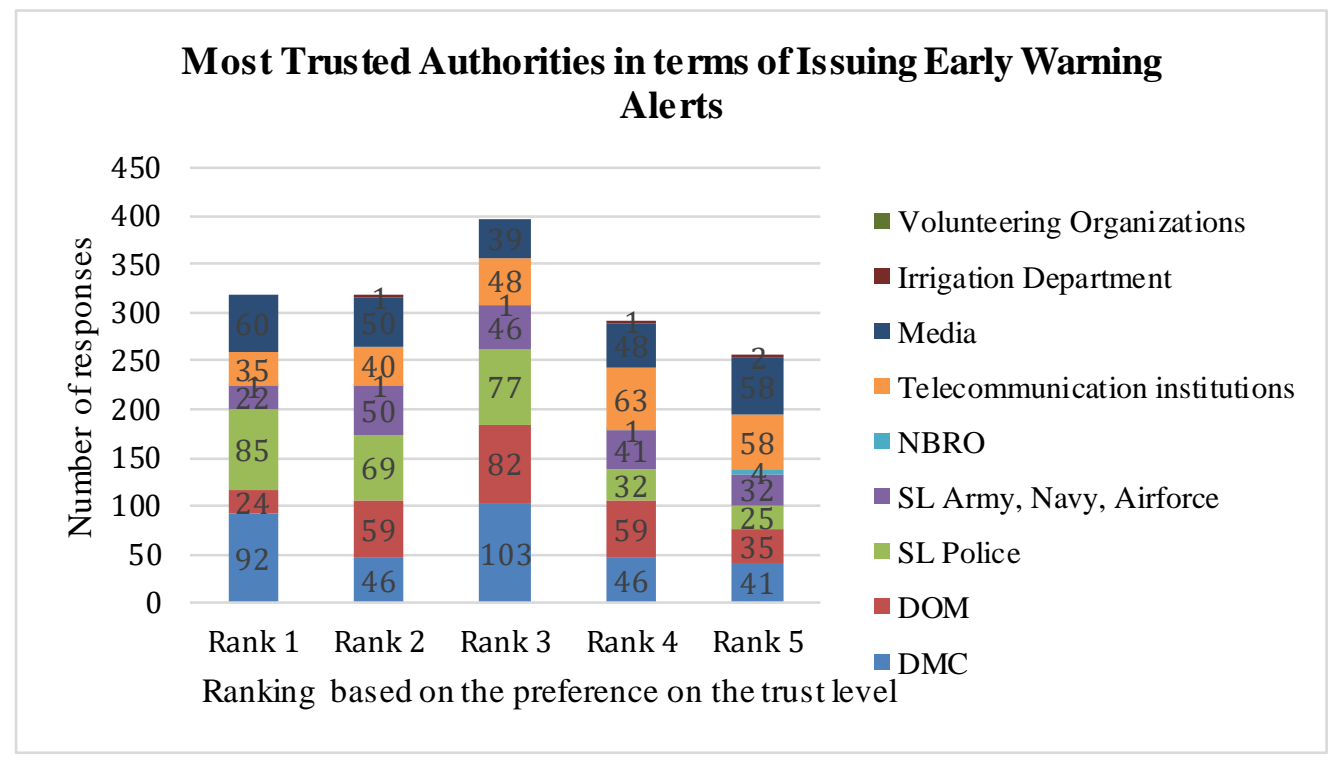

Figure 4 Most trusted institutions in issuing EW alert

As per the above representation, $92 \%$ of the responders have indicated that the Disaster Management Center is the most trusted authority in terms of issuing EW alerts. The next highly trusted authority was marked as the Sri Lanka Police, in which $85 \%$ of the responses were marked. The third highest trusted stakeholder is the Media, in which $60 \%$ of the responders have marked as the trusted authority. 
When classifying the responses based on the age category distribution of the responders, the most trusted authority as the Disaster Management Center was marked by the responders in age categories of below 18 years, 25-39 years and above 60 years. The responders between 18-24 years and 40-60 years have marked Sri Lanka Police as the most trusted stakeholder in terms of issuing the Early Warning alerts. These results can be considered towards verification of the EW messages when issuing to the community levels. Figure 5 represents the aforementioned overview based on the age category distribution.

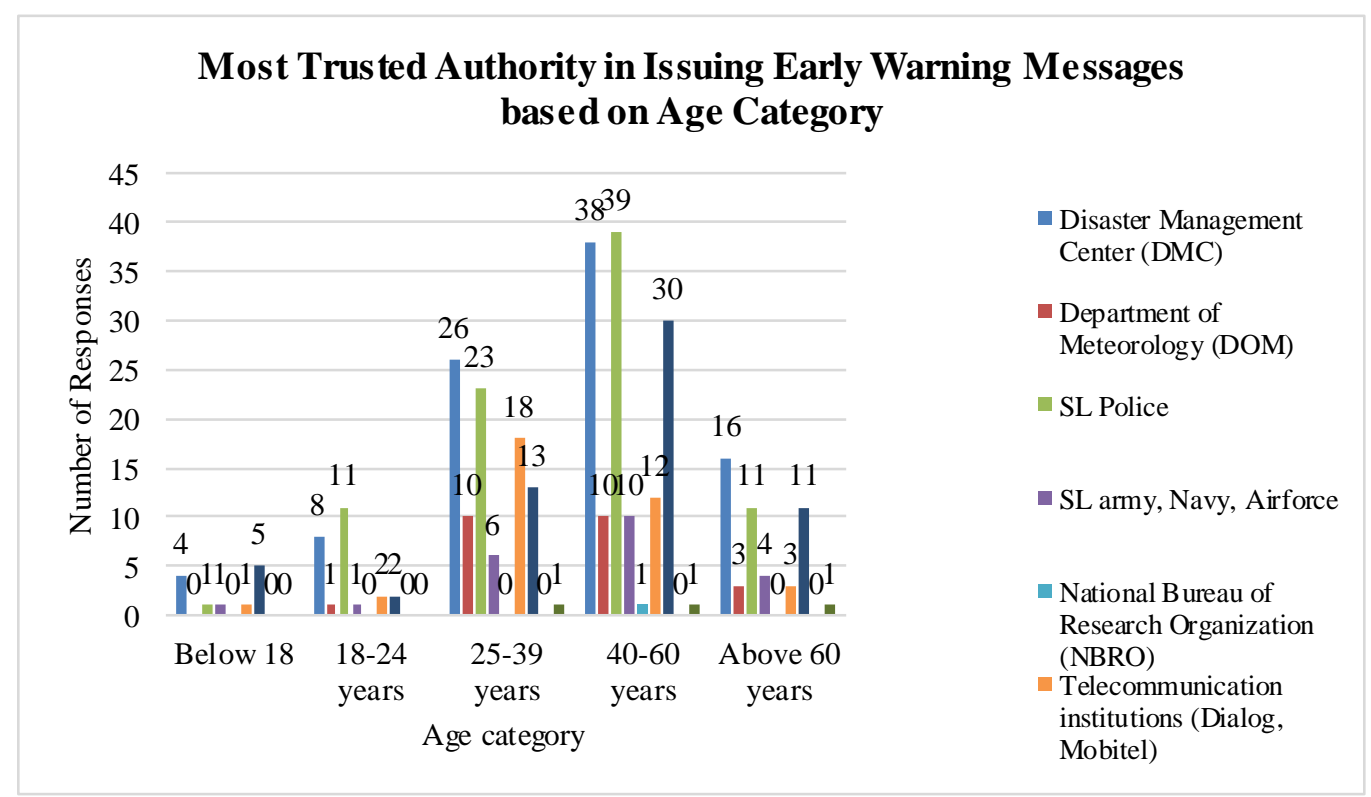

Figure 5 Most trusted authority based on the age category

The classification of the trusted stakeholders in terms of issuing EW alerts based on the gender category is represented in Figure 6. This summarizes, that $49 \%$ of the male trust towards Disaster Management Center in terms of issuing EW alerts and when considering the female response category, $52 \%$ of the females have marked Sri Lanka Police as the highest trusted stakeholder. 


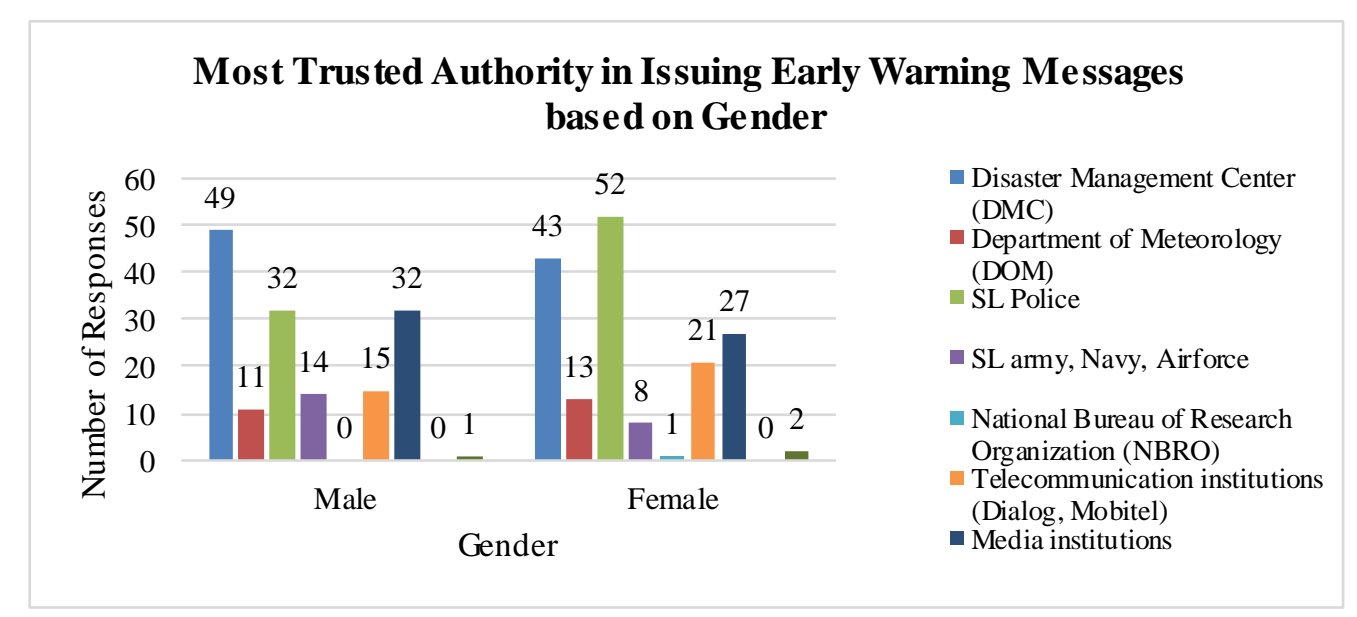

Figure 6 Most trusted authorities based on the age category

The summary of the responses received for the most trusted authorities in terms of issuing the MHEWs is denoted under Table 14. These results can be considered for the comparison between urban and rural levels considering the trusted authorities. Considering the urban and rural level comparison, in the urban community, most trusted authorities are recognized as Disaster Management Center (DMC), Telecommunication institutions, Sri Lanka Police, and Media institutions. From a rural level community perspective, the trust level is more based on the Disaster Management Center(DMC) only. This proves the impact of the government endorsement in issuing the EW alerts to the community where their trust is bound with.

Table 14 Most trusted authorities

\begin{tabular}{|c|c|c|c|c|c|c|c|c|}
\hline DS Division & GN Division & $\overline{\text { DMC }}$ & MET & SLP & $\begin{array}{l}\text { Tri } \\
\text { forces }\end{array}$ & NBRO & Telecom & $\begin{array}{l}\text { Medi } \\
\text { a }\end{array}$ \\
\hline \multirow[t]{4}{*}{ Bulathsinhala } & Bothalegamogoda & $43 \%$ & $18 \%$ & $12 \%$ & $18 \%$ & & $9 \%$ & \\
\hline & Paragoda East & $42 \%$ & $10 \%$ & $32 \%$ & $3 \%$ & & & $13 \%$ \\
\hline & $\begin{array}{l}\text { Amaragedara } \\
\text { South }\end{array}$ & $37 \%$ & $12 \%$ & $18 \%$ & & & $6 \%$ & $24 \%$ \\
\hline & Yatagampitiya & $44 \%$ & $3 \%$ & $36 \%$ & $11 \%$ & & $3 \%$ & $3 \%$ \\
\hline \multirow[t]{3}{*}{ Wattala } & Paranambalama & $23 \%$ & & $21 \%$ & $12 \%$ & & $23 \%$ & $15 \%$ \\
\hline & Uswetakeiyyawa & $20 \%$ & & $20 \%$ & $21 \%$ & & $15 \%$ & $18 \%$ \\
\hline & Dikowita & $19 \%$ & $9 \%$ & $34 \%$ & & & $13 \%$ & $19 \%$ \\
\hline \multirow[t]{3}{*}{ Colombo } & Grandpass South & $14 \%$ & & $32 \%$ & $11 \%$ & & $22 \%$ & $21 \%$ \\
\hline & Modara & $15 \%$ & & $23 \%$ & $4 \%$ & & $19 \%$ & $39 \%$ \\
\hline & Mattakkuliya & $19 \%$ & $8 \%$ & $38 \%$ & & & $8 \%$ & $27 \%$ \\
\hline
\end{tabular}

All these summarizes the variation of the trust level of the community on the stakeholders who are interlinked with the issuing of EW messages. These results can be 
considered for the further improvement of the enhancement of the effectiveness of the EW alerts.

\subsection{Visual Representation of the factors through Causal Loop Diagrams}

With this concern, the strength level towards the trustworthiness of society from the branched parameters of each of these two aspects are represented in the Causal Loop Diagram (CLD). Under this visual representation of the results obtained from the research study, the (+)ve symbol denotes the link between the parameters which lead towards the increase of community trust and the (-)ve symbol represents the influence towards the decrease of societal trust. Here, the considered modes of dissemination of the EW messages to the general public represent the influence towards the generation of trust towards the EW messages. These are more represented with the influence of the integration of mobile phone technology to the dissemination of the EW messages to the general public.

Accordingly, these general concepts of the summary of the results are visually represented under the below CLD. This way, the relationship and the influence of each of the considered parameters can be represented in a more perfect visualization as represented in Figure 7.

Here, in the focus of institutions which are issuing MHEWs, the Disaster Management Center, Media, Police, Tri forces, Telecommunication institutions and Department of Meteorology were identified as significant with the previous studies. Based on the existing trust level examination, the highest trust is on Disaster Management Center, which was denoted through the arrow link with highest thickness. The variation of arrow thickness denotes the variation of the strength of societal trustworthiness. Further, in the perspective of MHEW dissemination through mobile phones, the urban and rural level trustworthiness is represente here. The variation of the trustworthiness is represented accordingly with the varied thickness of the arrow in the visual representation diagram. Further, the variation of societal trustworthiness on modes of MHEW dissemination was represented under the visual representation here. The varying thickness of the arrow denotes the variation of societal trustworthiness in which the highest trust is denoted on traditional communication modes such as televisions, radio, loudspeakers and EW towers. 


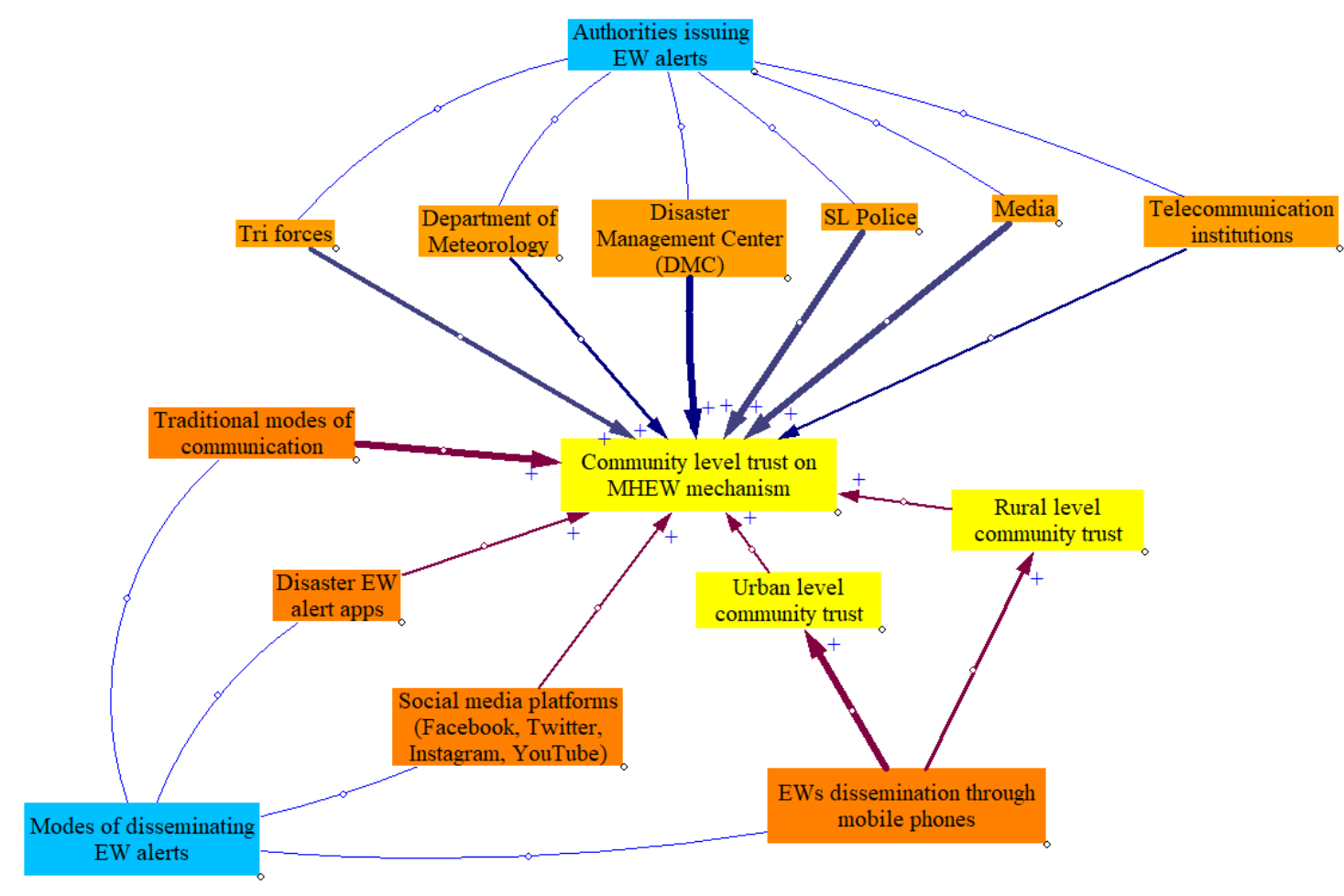

Figure 7 Societal trust behavior with identified parameters

\section{+ve sign - increasing the impact}

-ve sign - decreasing the impact

Thickness of the arrow - strength of the impact 


\section{Conclusion}

Under this research study, the level of societal trust towards the existing MHEW mechanism in Sri Lanka was studied. Further, the societal trust towards the mobile-based platforms which denotes the mode of warning dissemination was examined through the application of the Fuzzy logic approach. The variation of the parameters were further examined based on age, gender and urban and rural level basis. These were evaluated mainly based on similar variation studies done in the countries. From the overall analyzed results from the questionnaire survey, the following conclusions can be delivered.

The most trusted authorities in terms of issuing disaster EW alerts were identified by the community responses as Disaster Management Center (DMC), Sri Lanka Police (SLP) and the Media. Based on the trust level of the community, these institutions were reported as the most trusted institutions. 92\% of the responders have indicated that Disaster Management Center as the most trusted authority, $85 \%$ of the responses were marked as the second highest and $60 \%$ of the responders have marked Media as the trusted authority.

Based on the responses categorized on age distribution, age categories of below 18 years, 25-39 years and above 60 years have considered Disaster Management Center (DMC) as the most trusted stakeholder. This is more proven by the fact that DMC is recognized as the government endorsed body in the perspective of Disaster Management in Sri Lanka. The responders between 18-24 years and 40-60 years have marked Sri Lanka Police as the most trusted stakeholder. This is mainly as a result that, Sri Lanka Police act as the main coordinating body in reaching the communities in the societies during emergency disaster situations. Based on the gender category distribution, $49 \%$ of the males trust towards Disaster Management Center in terms of issuing EW alerts and when considering the female response category, $52 \%$ of the females have marked Sri Lanka Police as the highest trusted stakeholder. This is mainly because it was found from the face to face interviewing that most of the women are dedicated as housewives while men are dedicated to occupations in these examined areas. As a result, they mainly trust the governing bodies which are more commonly engaged in community awareness situations in the societies.

The trust level for the issuing of the EW alerts to the mobile-based applications was examined 5 points Likert scale and the results were analyzed using the Fuzzy Logic approach. The fuzzy logic results considering the triangular fuzzy numbers denote the community responders are more likely to trust the EW messages receiving to the mobile phones which implicates the applicability of mobile phone based platforms in the dissemination of EW alerts. Here, the Fuzzy logic approach was used to identify the most biased community response on the Likert scale response analysis. The triangular fuzzy numbers obtained under the urban and rural level community response analysis of the Likert scale imply that both the urban and rural level community are more likely to trust 
on adapting to the EWs delivered to mobile-based platforms. The urban level triangular fuzzy number of 4.8 implies a higher level of interest than the rural level triangular fuzzy number of 4.6. But, in consideration of both the values, the overall response is more biased towards the likeliness towards adaptation on the application of mobile based platforms in the EW alert dissemination mechanism.

Further, the correlation of determination was examined through IBM SPSS 22 software, among the variation of trust level behavior along with the level of importance of MHEW dissemination through mobile phone platform. Here the two variables denote a strong positive correlation and a polynomial behavioral relationship. To conclude the obtained results from this research study, the CLD was developed in denoting the visual perception and interrelation among each of the factors which influence the societal trust level in disaster situations.

In mainstreaming DRR strategies in the community and local level, the challenges which are triggered could be minimized through examining the gaps in existing mechanism. The growing complexity in the disaster risk environment lead the way to the policy makers and practitioners in developing the existing policy frameworks and strategies. In developing so, the societal trust plays a major role. Based on the societal trust level on the institutional perspectives of issuing MHEWs, the existing Standard Operation Procedures related with issuing MHEWs could be altered. This could be more efficiently upgraded with further focus on language, content and level of understandability of the MHEWs delivered to the community. Further, the actions need to be initiated so as to minimize the miscommunication of MHEWs with the minimizing of delivering false warning alerts to the community. In strengthening the trust level in the society, the strategic approaches can be implemented towards the specified gender categories and age groups in reaching and grabbing the MHEWs in effective manner. As obtained from the analyzed results, the trust is more strengthened with the content of the warning with the government endorsement. In reaching the community in dissemination of MHEWs, the institutions can deliver the warnings with the government endorsement proof in the body of the warning message. Further, the community awareness and level of understandability on MHEWs could be enhanced with community awareness sessions and training programs with the participation of different stakeholders linked with MHEW dissemination.

Further, in integrating the novel technological applications involved with MHEW, parameters such as timeliness, appropriateness, accuracy and simplicity need to be highly focused. As per the examined results under this study, the rural level trust towards modern technological platforms could be enhanced with well arranged awareness sessions and training drills. These could be arranged in a periodical manner to reach the rural level community, specially the youth category who can grab the technological aspects easily. Further, the accessibility and coverage in reaching the mobile based platforms needed to be developed with the future development plans integrated with DRR strategy implementation in the country. 


\section{Acknowledgment}

The authors here gratefully acknowledge Erasmus+ Capacity Building for Higher Education Grant, CApacity Building in Asia for Resilience EducaTion (CABARET) for providing funds and expertise in carrying out this research study. Further, the support provided by Dialog Axiata PLC in coordinating the field survey in this research study is highly appreciated.

\section{References}

[1] J. B. Barney and M. H. Hansen, "Trustworthiness as a Source of Competitive Advantage," Strategic Management Journal, vol. 15, no. S1, pp. 175-190, 1994, doi: https://doi.org/10.1002/smj.4250150912.

[2] J. X. Kasperson, R. E. Kasperson, N. Pidgeon, and P. Slovic, "The social amplification of risk: assessing fifteen years of research and theory," in The Social Amplification of Risk, N. Pidgeon, P. Slovic, and R. E. Kasperson, Eds. Cambridge: Cambridge University Press, 2003, pp. 13-46.

[3] J. D. White and K.-W. Fu, "Who Do You Trust? Comparing People-Centered Communications in Disaster Situations in the United States and China," Journal of Comparative Policy Analysis: Research and Practice, vol. 14, no. 2, pp. 126-142, Apr. 2012, doi: 10.1080/13876988.2012.664688.

[4] “The Art \& Science Of Early Disaster Warnings," Asian Scientist Magazine| Science, technology and medical news updates from Asia, Jan. 06, 2015. https://www.asianscientist.com/2015/01/features/art-science-early-disasterwarnings/ (accessed Nov. 09, 2019).

[5] J. Wang, Z. He, and W. Weng, "A review of the research into the relations between hazards in multi-hazard risk analysis," Nat Hazards, vol. 104, no. 3, pp. 2003-2026, Dec. 2020, doi: 10.1007/s11069-020-04259-3.

[6] S. Sufri, F. Dwirahmadi, D. Phung, and S. Rutherford, "A systematic review of Community Engagement (CE) in Disaster Early Warning Systems (EWSs)," Progress in Disaster Science, vol. 5, p. 100058, Jan. 2020, doi: 10.1016/j.pdisas.2019.100058.

[7] I. R. J. C. arts Science, "Role of Early warning system for Disaster Risk Reduction," Accessed: $\quad$ Feb. 20, 2019. [Online]. Available: https://www.academia.edu/27497389/Role_of_Early_warning_system_for_Disaster _Risk_Reduction.

[8] World Meteorological Organization, "Multi-hazard Early Warning Systems: A Checklist," p. 20, 2018.

[9] R. Samarajiva, "Policy Commentary: Mobilizing information and communications technologies for effective disaster warning: lessons from the 2004 tsunami," New Media \& Society, vol. 7, no. 6, pp. 731-747, Dec. 2005, doi: $10.1177 / 1461444805058159$.

[10] J. Zschau and A. N. Küppers, Early Warning Systems for Natural Disaster Reduction. Springer Science \& Business Media, 2013.

[11] R. Haigh, D. Amaratunga, and K. Hemachandra, "A capacity analysis framework for multi-hazard early warning in coastal communities," Procedia Engineering, vol. 212, pp. 1139-1146, Jan. 2018, doi: 10.1016/j.proeng.2018.01.147. 
[12] "Defining Multi-Hazard - Cascading and Interacting Natural Hazards." http//www.interactinghazards.com/defining-multi-hazard (accessed May 29, 2019).

[13] Word Meteorological "Multihazard_Early_Warning_Systems_A_Checklist," 2017. Accessed: Jan. 24, 2021. [Online]. Available: https://ane4bf-datap1.s3-eu-west1.amazonaws.com/wmocms/s3fs-public/ckeditor/files/Multihazard_Early_Warning_Systems_A_Checklist.pdf?fVgoQYM7LhPb3oR0V97j2.Qk js3Wc5Rq.

[14] M. Sakalasuriya, D. Amaratunga, R. Haigh, and S. Hettige, "A Study of The Upstream-downstream Interface in End-to-end Tsunami Early Warning and Mitigation Systems," International Journal on Advanced Science, Engineering and Information Technology, vol. 8, pp. 2421-2427, Dec. 2018, doi: 10.18517/ijaseit.8.6.7487.

[15] "India cyclone evacuation hailed a success," BBC News, May 04, 2019.

[16] Time, "India: Mass Evacuations as 'Extremely Severe' Cyclone Nears," Time. https:/time.com/5581606/cyc lone-fani-odisha-india/ (accessed Nov. 09, 2019).

[17] J. M. Rubiera Torres and M. A. Puig, "The Tropical Cyclone Early Warning System of Cuba," in Institutional Partnerships in Multi-Hazard Early Warning Systems: A Compilation of Seven National Good Practices and Guiding Principles, M. Golnaraghi, Ed. Berlin, Heidelberg: Springer, 2012, pp. 9-28.

[18] Groundviews, "Nurturing Public Trust in Times of Crisis: Reflections on April 11 Tsunami Warning," Groundviews, Apr. 26, 2012. https://groundviews.org/2012/04/26/nurturing-public-trust-in-times-of-crisisreflections-on-april-11-tsunami-warning/ (accessed Nov. 15, 2019).

[19] Alazeera, "Tens of thousands evacuated as cyclone approaches Sri Lanka," 2020. https://www.aljazeera.com/news/2020/12/2/sri-lanka-evacuates-thousands-ascyclone-burevi-nears (accessed Jan. 24, 2021).

[20] UNESCO, "Exercise Indian Ocean Wave 2020," 2020. http://www.ioctsunami.org/index.php?option=com_content \&view=article \&id=470:iowave20\&catid =20\&lang=en\&Itemid=68 (accessed Jan. 24, 2021).

[21] B. K. Paul, "Factors Affecting Evacuation Behavior: The Case of 2007 Cyclone Sidr, Bangladesh," The Professional Geographer, vol. 64, no. 3, pp. 401-414, Aug. 2012, doi: 10.1080/00330124.2011.609780.

[22] K. V. S. Badarinath, S. K. Kharol, A. R. Sharma, V. Ramaswamy, D. G. Kaskaoutis, and H. D. Kambezidis, "Investigations of an intense aerosol loading during 2007 cyclone SIDR - A study using satellite data and ground measurements over Indian region," Atmospheric Environment, vol. 43, no. 24, pp. 3708-3716, Aug. 2009, doi: 10.1016/j.atmosenv.2009.04.026.

[23] I. Alcántara-Ayala and A. Oliver-Smith, "Early Warning Systems: Lost in Translation or Late by Definition? A FORIN Approach," Int J Disaster Risk Sci, vol. 10, no. 3, pp. 317-331, Sep. 2019, doi: 10.1007/s13753-019-00231-3.

[24] I. Lopatovska and B. Smiley, "Proposed Model of Information Behaviour in Crisis: The Case of Hurricane Sandy," Information Research: An International Electronic Journal, vol. 19, no. 1, Mar. 2013, Accessed: May 31, 2020. [Online]. Available: https://eric.ed.gov/?id=EJ1020676.

[25] UNDRR and UNESCO-IOC, "Limitations and Challenges of Early Warning Systems; : A Case Study of the 2018 Palu-Donggala Tsunami," 2018. 
[26] C. W. Choo, "Information use and early warning effectiveness: Perspectives and prospects," J. Am. Soc. Inf. Sci., vol. 60, no. 5, pp. 1071-1082, May 2009, doi: 10.1002/asi.21038.

[27] S. Alizamir, F. de Véricourt, and S. Wang, "Warning Against Recurring Risks: An Information Design Approach," Management Science, Apr. 2020, doi: 10.1287/mnsc.2019.3420.

[28] C. Dupuy, V. Tutis, and K. Scharfenberg, "Cover: Courtesy of the Shanghai Meteorological Bureau," p. 25, 2010.

[29] P. L. A. I. Shehara, C. S. A. Siriwardana, D. Amaratunga, and R. Haigh, "Examining the Community Perception Towards Communication Modes of Issuing Multi-Hazard Early Warning (MHEW) in Sri Lanka," in 2020 Moratuwa Engineering Research Conference (MERCon), Jul. 2020, pp. 60-65, doi: 10.1109/MERCon50084.2020.9185325.

[30]D. S. Mileti and J. H. Sorensen, "Communication of emergency public warnings: A social science perspective and state-of-the-art assessment," Oak Ridge National Lab., TN (USA), ORNL-6609, Aug. 1990. doi: 10.2172/6137387.

[31] International Federation of Red Cross and Red Crescent Societie, "Community early warning systems: guiding principles." Koninklijke Brill NV, 2013, doi: 10.1163/2210-7975_HRD-9813-2015012.

[32] B. K. Paul and S. Dutt, "Hazard Warnings and Responses to Evacuation Orders: The Case of Bangladesh's Cyclone Sidr*," Geographical Review, vol. 100, no. 3, pp. 336355, 2010, doi: 10.1111/j.1931-0846.2010.00040.x.

[33] "Evacuation planning and people centred early warning_CSB.pptx." .

[34] P. L. A. I. Shehara, C. S. A. Siriwardana, D. Amaratunga, R. Haigh, and T. Fonseka, "Feasibility of Using Mobile Apps in Communication and Dissemination Process of Multi-hazard Early Warning (MHEW) Mechanism in Sri Lankan Context," in ICSECM 2019, Singapore, 2020, pp. 177-189, doi: 10.1007/978-981-15-7222-7_16.

[35] P. L. A. I. Shehara, C. S. A. Siriwardana, D. Amaratunga, and R. Haigh, "Application of Social Network Analysis (SNA) to Identify Communication Network Associated with Multi-Hazard Early Warning (MHEW) in Sri Lanka," in 2019 Moratuwa Engineering Research Conference (MERCon), Jul. 2019, pp. 141-146, doi: 10.1109/MERCon.2019.8818902.

[36] C. Randil, C. Siriwardana, and K. Hewawasam, "Framework to analyze Sri Lanka disaster management mechanism," International Journal of Disaster Resilience in the Built Environment, vol. 11, no. 2, pp. 289-307, Jan. 2019, doi: 10.1108/IJDRBE-072019-0044.

[37] UNDP, "Making Disaster Risk Reduction Gender Sensitive," 2009. Accessed: Mar. 13, 2021. [Online]. Available: https://www.unisdr.org/files/9922_MakingD isasterRiskReductionGenderSe.pdf.

[38] J. Twigg, "The Human Factor in Early Warnings: Risk Perception and Appropriate Communications," in Early Warning Systems for Natural Disaster Reduction, J. Zschau and A. Küppers, Eds. Berlin, Heidelberg: Springer, 2003, pp. 19-26.

[39] S. Brown, M. Budimir, A. Sneddon, D. Lau, P. Shakya, and S. Crawford, "Gender Transformative Early Warning Systems.pdf," 2019. Accessed: Mar. 13, 2021. [Online]. https://reliefweb.int/sites/reliefweb.int/files/resources/Gender\%20Transformative \%2 0Early\%20Warning\%20Systems.pdf. 
[40] B. Bjerge, N. Clark, P. Fisker, and E. Raju, "Technology and Information Sharing in Disaster Relief," PLOS ONE, vol. 11, no. 9, p. e0161783, Sep. 2016, doi: 10.1371/journal.pone.0161783.

[41] I. Shehara, C. Siriwardana, D. Amaratunga, and R. Haigh, "An Overview of Existing Digital Platforms in Disaster Emergency Response Stage," presented at the SBE19 Malta International Conference, Malta, 2019.

[42] H. M. S. S. Hippola et al., "Gap Assessment of Warning and Dissemination Process of Early Warning System in Coastal Areas of Sri Lanka," in ICSBE 2018, 2020, pp. 36-44.

[43] D. K. Rathnayake et al., "Barriers and enablers of coastal disaster resilience - lessons learned from tsunami in Sri Lanka," International Journal of Disaster Resilience in the Built Environment, vol. 11, no. 2, pp. 275-288, Jan. 2020, doi: 10.1108/IJDRBE07-2019-0050.

[44] G. P. Jayasiri, O. P. C. Randil, G. M. C. A. Perera, C. S. A. Siriwardana, P. B. R. Dissanayake, and C. S. Bandara, "Important Aspects of Evacuation Planning for the Coastal Communities in Sri Lanka," in ICSBE 2018, Singapore, 2020, pp. 3-10, doi: 10.1007/978-981-13-9749-3_1.

[45] C. Perera et al., "Evaluation of gaps in early warning mechanisms and evacuation procedures for coastal communities in Sri Lanka," International Journal of Disaster Resilience in the Built Environment, vol. 11, no. 3, pp. 415-433, Jan. 2020, doi: 10.1108/IJDRBE-07-2019-0048.

[46] D. Paton, "Preparing for natural hazards: the role of community trust," Disaster Prevention and Management: An International Journal, vol. 16, no. 3, pp. 370-379, Jan. 2007, doi: 10.1108/09653560710758323.

[47] L. Peng, J. Tan, W. Deng, and Y. Liu, "Farmers' participation in community-based disaster management: The role of trust, place attachment and self-efficacy," International Journal of Disaster Risk Reduction, vol. 51, p. 101895, Dec. 2020, doi: 10.1016/j.jjdrr.2020.101895.

[48] T. Motoyoshi, "Public Perception of Flood Risk and Community-based Disaster Preparedness," p. 14, 2006.

[49] M. Malesic, "The concept of trust in disasters: the Slovenian experience," Disaster Prevention and Management: An International Journal, vol. 28, no. 5, pp. 603-615, Jan. 2019, doi: 10.1108/DPM-11-2018-0375.

[50] N. Kapucu, T. Arslan, and F. Demiroz, "Collaborative emergency management and national emergency management network," Disaster Prevention and Management: An International Journal, vol. 19, no. 4, pp. 452-468, Jan. 2010, doi: 10.1108/09653561011070376.

[51] G. V. Wyk, A Systems Approach to Social and Organizational Planning: Cure for the Mess in Health Care? Trafford Publishing, 2003.

[52]M. Rehak, M. Gregor, and M. Pechoucek, "Multidimensional Context Representations for Situational Trust," in IEEE Workshop on Distributed Intelligent Systems: Collective Intelligence and Its Applications (DIS'06), Jun. 2006, pp. 315320, doi: 10.1109/DIS.2006.54.

[53] M.-J. Sule, M. Li, G. Taylor, and C. Onime, "Fuzzy logic approach to modelling trust in cloud computing," IET Cyber-Physical Systems: Theory Applications, vol. 2, no. 2, pp. 84-89, 2017, doi: 10.1049/iet-cps.2017.0016.

[54] F. Akhter, D. Hobbs, and Z. Maamar, "A fuzzy logic-based system for assessing the level of business-to-consumer (B2C) trust in electronic commerce," Expert Systems 
with Applications, vol. 28, no. 4, pp. 623-628, May 2005, doi: 10.1016/j.eswa.2004.12.039.

[55] M. Nilashi, O. Ibrahim, V. Reza Mirabi, L. Ebrahimi, and M. Zare, "The role of Security, Design and Content factors on customer trust in mobile commerce," Journal of Retailing and Consumer Services, vol. 26, pp. 57-69, Sep. 2015, doi: 10.1016/j.jretconser.2015.05.002.

[56]Z. Wei, L. Lu, and Z. Yanchun, "Using fuzzy cognitive time maps for modeling and evaluating trust dynamics in the virtual enterprises," Expert Systems with Applications, vol. 35, no. 4, pp. 1583-1592, Nov. 2008, doi: 10.1016/j.eswa.2007.08.071.

[57] R. J. Lewicki, E. C. Tomlinson, and N. Gillespie, "Models of Interpersonal Trust Development: Theoretical Approaches, Empirical Evidence, and Future Directions:," Journal of Management, Jul. 2016, doi: 10.1177/0149206306294405.

[58] D. H. McKnight and N. L. Chervany, "What is Trust? A Conceptual Analysis and an Interdisciplinary Model," p. 8.

[59] M. Laeequddin, B. S. Sahay, V. Sahay, and K. Abdul Waheed, "Trust building in supply chain partners relationship: an integrated conceptual model," Journal of Management Development, vol. 31, no. 6, pp. 550-564, Jan. 2012, doi: $10.1108 / 02621711211230858$.

[60] J. Jagosh et al., "A realist evaluation of community-based participatory research: partnership synergy, trust building and related ripple effects," BMC Public Health, vol. 15, no. 1, p. 725, Jul. 2015, doi: 10.1186/s12889-015-1949-1.

[61] M. I. Reed, "Organization, Trust and Control: A Realist Analysis," Organization Studies, vol. 22, no. 2, pp. 201-228, Mar. 2001, doi: 10.1177/0170840601222002.

[62] A. Madill, A. Jordan, and C. Shirley, "Objectivity and reliability in qualitative analysis: Realist, contextualist and radical constructionist epistemologies," British Journal of Psychology, vol. 91, no. 1, pp. 1-20, 2000, doi: 10.1348/000712600161646.

[63]C. Hui, M. Goldberg, M. Magdon-Ismail, and W. A. Wallace, "Agent-based simulation of the diffusion of warnings," in Proceedings of the 2010 Spring Simulation Multiconference, Orlando, Florida, Apr. 2010, pp. 1-8, doi: 10.1145/1878537.1878547.

[64] A. Crooks, C. Castle, and M. Batty, "Key challenges in agent-based modelling for geo-spatial simulation," Computers, Environment and Urban Systems, vol. 32, no. 6, pp. 417-430, Nov. 2008, doi: 10.1016/j.compenvurbsys.2008.09.004.

[65] K. H. van Dam, I. Nikolic, and Z. Lukszo, Agent-Based Modelling of Socio-Technical Systems. Springer Science \& Business Media, 2012.

[66] V. A. Chanley, T. J. Rudolph, and W. M. Rahn, "The Origins and Consequences of Public Trust in Government: A Time Series Analysis," Public Opin Q, vol. 64, no. 3, pp. 239-256, Nov. 2000, doi: 10.1086/317987.

[67] N. Ramadan and A. M., "A Fuzzy Logic Framework for Evaluating the Security Features of Banknotes," International Journal of Computer Applications, vol. 179, no. 51, pp. 39-47, Jun. 2018, doi: 10.5120/ijca2018917338.

[68] S. de la Rosa de Sáa, M. Á. Gil, M. T. L. García, and M. A. Lubiano, "Fuzzy Rating vs. Fuzzy Conversion Scales: An Empirical Comparison through the MSE," in Synergies of Soft Computing and Statistics for Intelligent Data Analysis, Berlin, Heidelberg, 2013, pp. 135-143, doi: 10.1007/978-3-642-33042-1_15. 
[69] “Cavdaroglu - 2019 - Bulanık Küme Teorisinin Müşteri Memnuniyeti Karş1.pdf.” Accessed: Nov. $09, \quad 2019 . \quad$ [Online]. Available: https://dergipark.org.tr/tr/download/artic le-file/672965.

[70] "Disaster Information Management system in Sri Lanka." http://www.desinventar.lk/ (accessed Nov. 08, 2019).

[71]K. S. Taber, "The Use of Cronbach's Alpha When Developing and Reporting Research Instruments in Science Education," Res Sci Educ, vol. 48, no. 6, pp. 1273 1296, Dec. 2018, doi: 10.1007/s11165-016-9602-2.

[72] V. Anandan and G. Uthra, "Defuzzification by area of region and decision making using Hurwicz criteria for fuzzy numbers," Applied Mathematical Sciences, vol. 8, pp. 3145-3154, 2014, doi: 10.12988/ams.2014.44294.

[73] "Cavdaroglu - 2019 - Bulanı Küme Teorisinin Müşteri Memnuniyeti Karş1.pdf.” Accessed: Nov. $2019 . \quad$ [Online]. Available: https://dergipark.org.tr/tr/download/artic le-file/672965.

[74] B. Weeraratne, "Re-Defining Urban Areas in Sri Lanka.," ResearchGate, 2016. https://www.researchgate.net/publication/314257911_ReDefining_Urban_Areas_in_Sri_Lanka (accessed Nov. 08, 2019).

[75] A. H. Murphy, "The Coefficients of Correlation and Determination as Measures of performance in Forecast Verification," Wea. Forecasting, vol. 10, no. 4, pp. 681-688, Dec. 1995, doi: 10.1175/1520-0434(1995)010<0681:TCOCAD>2.0.CO;2.

[76] A. P. Reynolds and F. Duvall, "Digital Image Correlation for Determination of Weld and Base MetalConstitutive Behavior," p. 6.

[77] S. Menard, "Coefficients of Determination for Multiple Logistic Regression Analysis," The American Statistician, vol. 54, no. 1, pp. 17-24, Feb. 2000, doi: 10.1080/00031305.2000.10474502. 